\title{
Exposure to organic solvents and neuropsychological dysfunction: a study on monozygotic twins
}

\author{
Helena Hänninen, Mari Antti-Poika, Juhani Juntunen, Markku Koskenvuo
}

\begin{abstract}
Twenty one monozygotic twins exposed to organic solvents were compared with their non-exposed cotwins by performance in psychological tests. A further 28 monozygotic twin pairs were examined as a reference group. The study used 11 tests, 10 of which had shown an effect in previous studies on the results of exposure to solvents. Paired comparisons of the test scores showed the exposed twins to have lower performance in associative learning, digit span, and block design. These results agree with two previous studies that used a similar set of tests. Contrary to some other studies, psychomotor speed was not affected, but the results indicated a marginal effect on the control of hand movements. Further comparison of subgroups with a low and a high exposure showed the prevalence of subtle neuropsychological dysfunction to be greater among the more exposed twins.
\end{abstract}

Several authors have reported subclinical psychological dysfunction among workers exposed to organic solvents. Nevertheless, the behavioural toxicity of mixtures of organic solvents is still a matter of dispute. Not all studies dealing with solvent mixtures showed an effect, ${ }^{1-3}$ and those that did are rather inconsistent with regard to the type of dysfunction found; the pattern was sometimes dominated by cognitive dysfunction, ${ }^{4-6}$ sometimes by psychomotor retardation, ${ }^{7}$ and sometimes by subjective symptoms and mood changes. ${ }^{8-9}$ Plausible explanations for the differing results include qualitative and quantitative differences in exposure, differences in age structure and other characteristics of the subjects under study,

Institute of Occupational Health, Helsinki, Finland $H$ Hänninen

M Antti-Poika

Employment Pension Fund (LEL), Helsinki, Finland J Juntunen

Department of Public Health, University of Turku, Finland

M Koskenvuo and differences in the test methods applied. Moreover, the large interindividual variation in behavioural tests, and the far from perfect accuracy of such tests can easily produce "results" by chance. Finally, systematic bias, either positive or negative, cannot be ruled out because of the numerous possible confounders in behavioural studies. The availability of well matched reference subjects is crucial for psychological epidemiological studies.

In this study the subject group consisted of monozygotic twins exposed to solvents, with their non-exposed cotwins as controls. Thus matching of the exposed subjects and their controls with regard to biological heritage, childhood conditions, and age was achieved.

The study focused on three questions: Are there systematic intrapair differences indicating adverse solvent effects among the exposed twins? Are the intrapair differences related to the exposure dose? Which tests, if any, indicate a neurotoxic effect?

\section{Method}

SUBJECTS

The Finnish twin cohort is a nationwide register of like-sexed adult twins with 4300 pairs of monozygotic twins. ${ }^{10}$ In the 1981 questionnaire study of the twin cohort 60 pairs had reported to be discordant for solvent exposure-that is, one twin had been exposed to organic solvents whereas the cotwin had not. A more detailed questionnaire was sent to these 60 pairs. Thirty pairs seemed to be discordant and were invited to join the study. In the interview, six pairs were found not to be truly discordant and were excluded, as were three pairs whose examinations were incomplete. The remaining 21 pairs of twins (11 pairs of men, 10 pairs of women) formed the solvent pairs (S pairs) of our study. The exposed twins ( $E$ twins) were the study subjects, and the non-exposed cotwins (non-E twins) served as their controls.

A further 28 pairs of monozygotic twins (14 pairs of men, 14 pairs of women) of similar age, picked from the Twin Register and willing to participate in the study, gave extra reference material; these were referred to as the reference pairs ( $R$ pairs). The age range of the $S$ pairs was $28-55$ (median 42 years), and that of the $R$ pairs 29-64 (median 41 years). 
Table 1 describes the formal education and occupational state of the $S$ pairs. In three pairs the non-E twin had had a college education, whereas the $E$ twins' education had been less formal. In two of these pairs the non-E twin also had a higher occupational state. The rest of the pairs had a roughly corresponding education and occupational state.

All the $S$ pairs were found to be concordant for the use of alcohol according to the 1981 questionnaire study. In the clinical interview, however, one pair was found to be discordant because the non-E twin used alcohol regularly, whereas the $\mathrm{E}$ twin never used alcohol.

None of the E twins were claiming or had ever claimed for compensation for occupational risks.

\section{EXPOSURE OF THE E TWINS}

The most common occupations of the $\mathrm{E}$ twins were related to painting or gluing. The solvents most commonly used were petroleum benzene type solvent mixtures consisting mainly of aliphatic hydrocarbons. Many people had also been exposed to aromatic hydrocarbons such as toluene and xylene. Five people had also been exposed to some extent to chlorinated hydrocarbons such as tri- or tetrachloroethylene, methylene chloride, or 1,1,1trichloroethane.

The occupational history, including a detailed description of working conditions during separate time periods, was obtained by an occupational health physician. No environmental measures had been undertaken at the subjects' workplaces. Based on the work descriptions, an industrial hygienist evaluated the degree of exposure for each work task, and the lifetime average exposure was then calculated. Besides the data from the history, all other data available from the workplace were used in the evaluation, as was the general experience of the institute about the exposure in similar working conditions. Because the workers were always exposed to solvent mixtures, exposure was expressed as a sum percentage of the hygienic standards according to the method of the American conference of governmental industrial hygienists. ${ }^{11}$

The duration of exposure was 5-30 years (median duration 13 years). The estimated average lifetime exposure was $10-100 \%$ of the Finnish hygiene standard (HS) (median 30\%). The exposure had mostly been higher in previous years than at the time of examination. The exposure was still continuing for 13 people, whereas seven had not been exposed for the last two to nine years, and one not for 16 years. An exposure index was formed to express the number of hygienic standard years (theoretical duration of exposure in years if the exposure had been constant at $100 \%$ of the hygienic standard).

Two exposure groups, labelled E1 twins and E2 twins were formed based on the exposure index (table 2). Only a few people had both a long and a high exposure that would have produced high exposure indices. More often, either the duration of exposure was short or the degree of exposure was low.

All the $\mathrm{E}$ twins with less formal education than their cotwins were in group E1.

\section{THE TEST METHODS}

The psychological testing was part of a thorough medical examination conducted at the Institute of

Table 1 Formal education (FE) and occupation of the twins

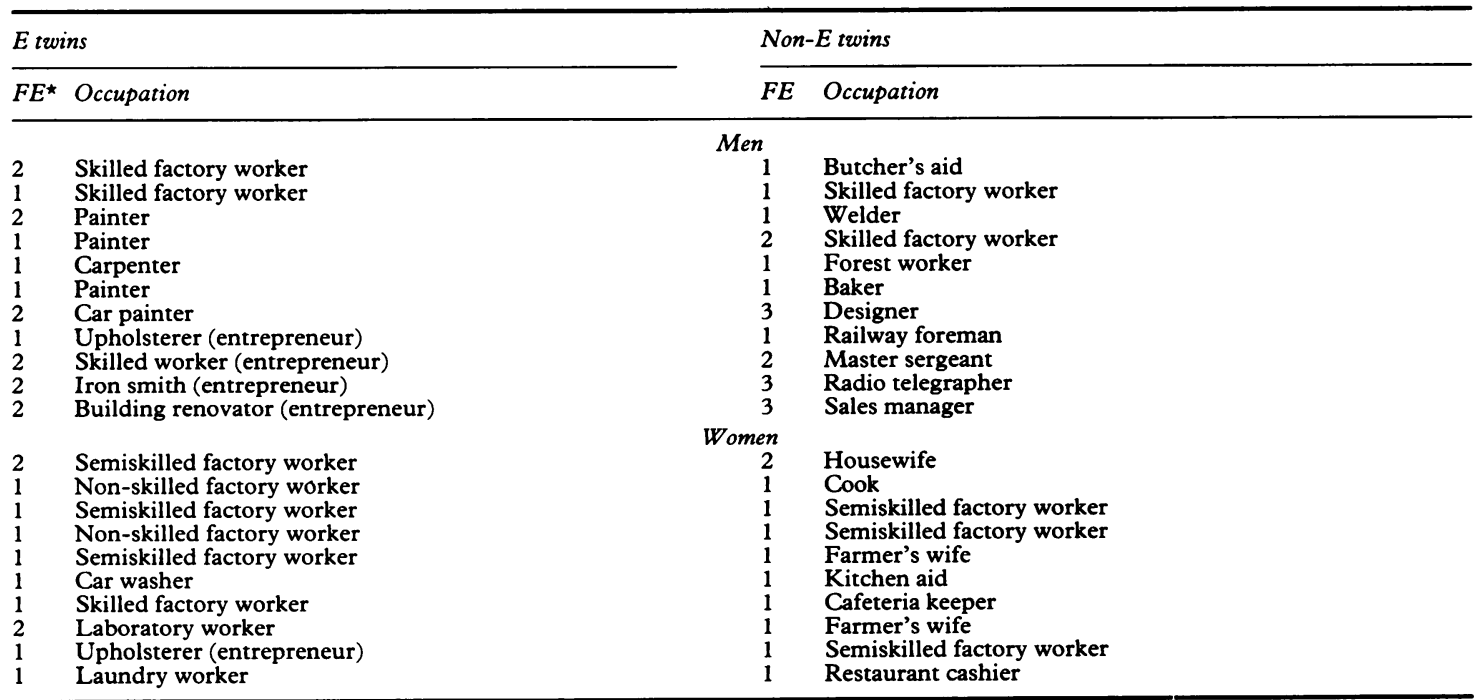

$\star^{\star} 1=$ Comprehensive school; 2 = comprehensive school plus vocational school; $3=$ college education. 
Table 2 Exposure of $E$ twins in subgroups with lower (group E1) and higher (E2) exposure index (the median value of the overall exposure index was used as the cut off point between the two subgroups)

\begin{tabular}{|c|c|c|c|c|c|c|c|}
\hline \multirow[b]{3}{*}{ Group } & \multirow[b]{3}{*}{ No of subjects } & \multicolumn{6}{|l|}{ Exposure } \\
\hline & & \multicolumn{2}{|c|}{ Exposure index } & \multicolumn{2}{|c|}{ Duration } & \multicolumn{2}{|l|}{ Level } \\
\hline & & Range & Median & Range & Median & Range & Median \\
\hline $\begin{array}{l}\text { E1 } \\
\text { E2 }\end{array}$ & $\begin{array}{l}11 \\
10\end{array}$ & $\begin{array}{l}0 \cdot 7-3 \cdot 0 \\
4 \cdot 0-12 \cdot 0\end{array}$ & $\begin{array}{l}1 \cdot 7 \\
5 \cdot 5\end{array}$ & $\begin{array}{l}3-26 \\
8-26\end{array}$ & $\begin{array}{l}10 \\
19\end{array}$ & $\begin{array}{c}5-100 \\
20-50\end{array}$ & $\begin{array}{l}20 \\
40\end{array}$ \\
\hline
\end{tabular}

Occupational Health. ${ }^{12}$ The examination lasted for two days and about two hours were reserved for the psychological tests. These were given by a well trained psychology student who did not know which twin was the exposed one, nor whether the pair belonged to the solvent group or to the reference group. The tests were given on the second day of examinations, so that exposure had ceased over 40 hours earlier.

The tests measured psychomotor abilities, attention, verbal and visual intelligence, memory, and emotional reactions. With the exception of the Stroop test, they were selected from methods used in previous solvent and lead studies at the Institute. Table 3 lists the tests and refers to the previous studies.

Similarities (Sim), block design (BD), and digit symbol (DSy) tests were given and scored according to the Wechsler Adult Intelligence Scale (WAIS) manual, ${ }^{20}$ and the digit span (DSp) test according to the manual for WAIS-R. ${ }^{21}$ The associative learning (AssL) test ${ }^{22}$ was modified from the original to contain five easy and five difficult word pairs to learn. The variable, AssL1, was the traditional score, half a point for each correctly recalled easy pair and one point for each difficult pair. The variable, AssL2, was the number of correctly recalled pairs at the last learning trial. AssL was given at the start of the session. A retention trial was the last test in the series. The variable, AssRet, was the number of correct recalls at this trial.

Table 3 Test methods and references to previous studies where the method was used

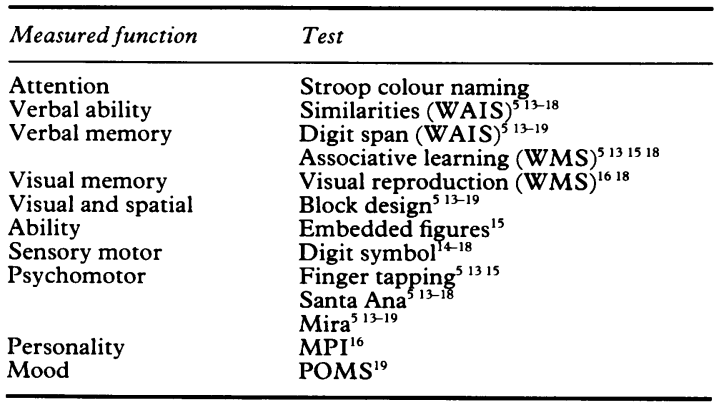

The visual reproduction (VisR) test was conducted according to the Wechsler Memory Scale manual. The embedded figures (EF) test was the pattern recognition task of Valciukas and Singer. ${ }^{23}$ The score (variable EF) was the total number of correctly identified figures. The Stroop colour naming test, used in its original form, had three subtasks: reading colour names written in black (Stroop1), naming the colours of coloured dots (Stroop2), and naming the colours of colour names written in different colours to the one indicated by the written text (Stroop3). Scores were the performance times.

Instruction for the Santa Ana dexterity test differed from the usual one ${ }^{24}$ in that the subjects had to turn the pegs 90 degrees instead of 180 degrees. The task was performed with the right (or preferred) hand (SA1), with the left (or non-preferred) hand (SA2), and with both hands simultaneously (SA3). Subtasks for the finger tapping test were, correspondingly, the right hand (FT1) and the left hand (FT2) performances. ${ }^{24}$

For the Mira test, the staircase task ${ }^{24}$ was used. In it the subject draws stairs according to the model given on the test sheet, first upwards and then downwards, without seeing his hand and his performance except at the beginning of the task. The variables were the sizes of the drawings by the right (Miral) and the left (Mira2) hand, and rated disorganisation of the stair pattern (Mira3).

POMS was the Finnish version of the profile of mood states, consisting of eight mood scales ${ }^{19}$ and MPI was a short version of the Maudsley personality inventory.

Scoring of Sim, EF, visual retention, and Mira was carried out by two independent psychologists who were "blind" with regard to pair, exposure, and group. On the rare occasions of discrepancy a consensus decision was easily reached. For the differing scores in VisR a third psychologist acted as a referee. For all tests, raw scores were used in the statistical analyses.

\section{Results}

MEANS OF THE INTRAPAIR DIFFERENCES

Intrapair differences for the test scores were evaluated by the one sided $t$ test for paired comparisons. For the $\mathrm{S}$ pairs, the difference was the score of 
the $\mathrm{E}$ twin minus the score of the non-E twin. Corresponding differences for the $S$ pairs were calculated according to the identification numbers of the twins in our data; the "evens" were subtracted from the "odds".

Three cognitive tests (AssL, DSp, and BD) showed statistically significant differences between the $\mathrm{E}$ and non-E twins (table 4). The results were statistically significant for all three AssL variables, with the highest level of significance for AssL2. Similarities (Sim), which can be taken as a measure of initial intelligence and education, were the same in both groups, as was the EF. In the Stroop test, the E twins tended to be slower in the cognitive interference task (Stroop3), but this difference was not statistically significant. For the $\mathbf{R}$ pairs the mean intrapair differences were small but most of the standard deviations (SDs) were of the same order as for the $S$ pairs. Thus the size of the intrapair differences was about the same in both groups of twin pairs, but the differences were systematic within the $S$ pairs, so that the $E$ twins usually had poorer performances than the non-E twins.

Table 4 Mean intrapair differences in the solvent pairs $(S)$ $(n=21)$ and reference pairs $(R)(n=28)$ : cognitive tests

\begin{tabular}{|c|c|c|c|c|}
\hline \multirow[b]{2}{*}{ Test variable } & \multicolumn{2}{|l|}{ Group $S$} & \multicolumn{2}{|l|}{ Group $R$} \\
\hline & Mean (SD) & $t \dagger$ & Mean (SD) & $t \dagger$ \\
\hline 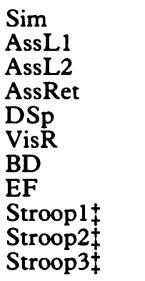 & $\begin{array}{l}0.3(3.6) \\
-16.2(39.8) \\
-1.1(1.9) \\
-1.1(2.2) \\
-1.5(2.9) \\
-\quad 0.4(3.4) \\
-\quad 3.0(5.7) \\
-\quad 0.2(2.6) \\
-\quad 0.5(10.3) \\
-\quad 1.8(17.4) \\
7.6(30.7)\end{array}$ & $\begin{array}{l}0.369 \\
-1 \cdot 862^{\star} \\
-2 \cdot 613^{\star \star} \\
-2 \cdot 408^{\star} \\
-2 \cdot 386^{\star} \\
-0.514 \\
-2 \cdot 448^{\star \star} \\
-0.413 \\
-0.212 \\
-0.476 \\
1 \cdot 129\end{array}$ & $\begin{array}{l}0.6(2.8) \\
-4.2(38.8) \\
-0.3(1.3) \\
-0.1(1.3) \\
-0.3(3.3) \\
-0.4(2.2) \\
1.2(7.1) \\
-1.2(4.6) \\
-1.0(9.4) \\
-0.5(10.8) \\
-0.2(21.6)\end{array}$ & $\begin{array}{r}1.139 \\
-0.584 \\
-1.137 \\
-0.583 \\
-0.403 \\
-0.860 \\
0.881 \\
-1.346 \\
-0.544 \\
-0.210 \\
-0.508\end{array}$ \\
\hline
\end{tabular}

${ }^{\star} \mathrm{p}<0.1 ;{ }^{\star} \mathrm{p}<0.01$.

†One sided $t$ test for paired comparisons.

$\ddagger$ Lower score indicates better performance.

Table 5 Mean intrapair differences in the solvent pairs (group $S)(n=21)$ and reference pairs (group $R$ ) $(n=28):$ psychomotor tests

\begin{tabular}{|c|c|c|c|c|}
\hline \multirow[b]{2}{*}{ Test variable } & \multicolumn{2}{|l|}{ Group $S$} & \multicolumn{2}{|l|}{ Group $R$} \\
\hline & Mean (SD) & $t \dagger$ & Mean (SD) & $t \dagger$ \\
\hline $\begin{array}{l}\text { DSy } \\
\text { SA1 } \\
\text { SA2 } \\
\text { SA3 } \\
\text { FT1 } \\
\text { FT2 } \\
\text { Mira1 } \\
\text { Mira2 } \\
\text { Mira3† }\end{array}$ & $\begin{array}{r}2.3(5.2) \\
-1.0(6.8) \\
-1.8(4.6) \\
-0.7(5.9) \\
2.7(11.4) \\
-0.6(10.6) \\
-1.8(4.9) \\
-0.4(3.4) \\
0.3(1.2)\end{array}$ & $\begin{aligned} & 2 \cdot 004^{\star} \\
&-0.671 \\
&-1 \cdot 742^{\star} \\
&-0.516 \\
& 1.089 \\
&-0.269 \\
&-1.701 \\
&-0.580 \\
& 1.101\end{aligned}$ & $\begin{array}{r}-1.8(8.2) \\
0.3(6.4) \\
-1.2(5.9) \\
0.1(7.0) \\
-2.0(11.2) \\
-3.4(10.1) \\
0.2(4.0) \\
0.9(2.8) \\
0.1(0.9)\end{array}$ & $\begin{array}{r}-0.251 \\
0.207 \\
-1.093 \\
0.054 \\
-0.931 \\
-1.772 \star \\
0.237 \\
1.621 \\
0.420\end{array}$ \\
\hline
\end{tabular}

$\star \mathrm{p}<0.05$.

tOne sided $t$ test for paired comparisons.

$\ddagger$ Lower score indicates better performance.
The psychomotor tests showed no consistent differences between the $\mathrm{E}$ and non- $\mathrm{E}$ twins. The $\mathrm{E}$ twins were faster in DSy but were slower in SA2 and tended to have clumsier performances in Mira (table 5). One psychomotor variable gave a statistically significant intrapair difference for the $R$ pairs.

The figure illustrates the differences between the $E$ and non-E twins in the four cognitive test variables with highest $t$ values for the inferiority of the $\mathrm{E}$ twins. In AssL, two thirds of the non-E twins but only one third of the $\mathrm{E}$ twins had, after three trials, learned nine or 10 of the associated word pairs. In DSp and BD twin pairs either had similar scores to each other or the $\mathrm{E}$ twin had a lower score. Performance times in Stroop3 were longer for the E twins, but one pronounced difference occurred in the opposite direction.

The means of the intrapair differences for the POMS and MPI scales were, in general, small for both the $S$ and the $R$ pairs. Absentmindedness gave a statistically significant difference, however, for the $S$ pairs, and fatigue gave a significant difference for the $R$ pairs (table 6 ).

\section{THE COMPOSITE INTRAPAIR DIFFERENCE SCORE}

IN SUBGROUPS

The exposure response relation was examined by comparing the distributions of a composite intrapair difference (CID) score of the twins with the lower (E1 twins) and the higher (E2 twins) exposure. A corresponding comparison was made between the $S$ pairs and the $R$ pairs. Nine test variables (table 7) representing different aspects of performance were chosen to make up the CID score. The $\mathrm{E}$ twins had a poorer performance in all selected tests irrespective of statistical significance (tables 4 and 5). AssL, Stroop, SA, and FT were represented by one variable only; Mira by two variables. For each of these variables an intrapair difference was counted as a real difference when it equalled or exceeded $1 \mathrm{SD}$ (or, in the case of a skew distribution, half of the difference between the 25th and 75th percentiles) in an unpublished larger study of twins. The CID score was calculated as the number of tests in which the $\mathrm{E}$ twin was better than the cotwin minus the number of tests in which the $\mathrm{E}$ twin had a poorer performance. The CID score for the $S$ pairs was the difference between twins with odd and even numbers.

Table 8 shows the part that each of the tests had in the CID score. It gives the prevalence of positive ( $E$ twin better) and negative ( $\mathrm{E}$ twin worse) differences yielded by the nine test variables within the $S$ pairs. In DSp, BD, SA2, and Mira3 none of the $E$ twins was the better one. The result was, however, statistically significant only for AssL2, BD, and Mira1. The proportions of worse performances tended to be higher for the E2 twins than for the E1 twins but, except for AssL2, the differences between the subgroups were not statistically significant. 

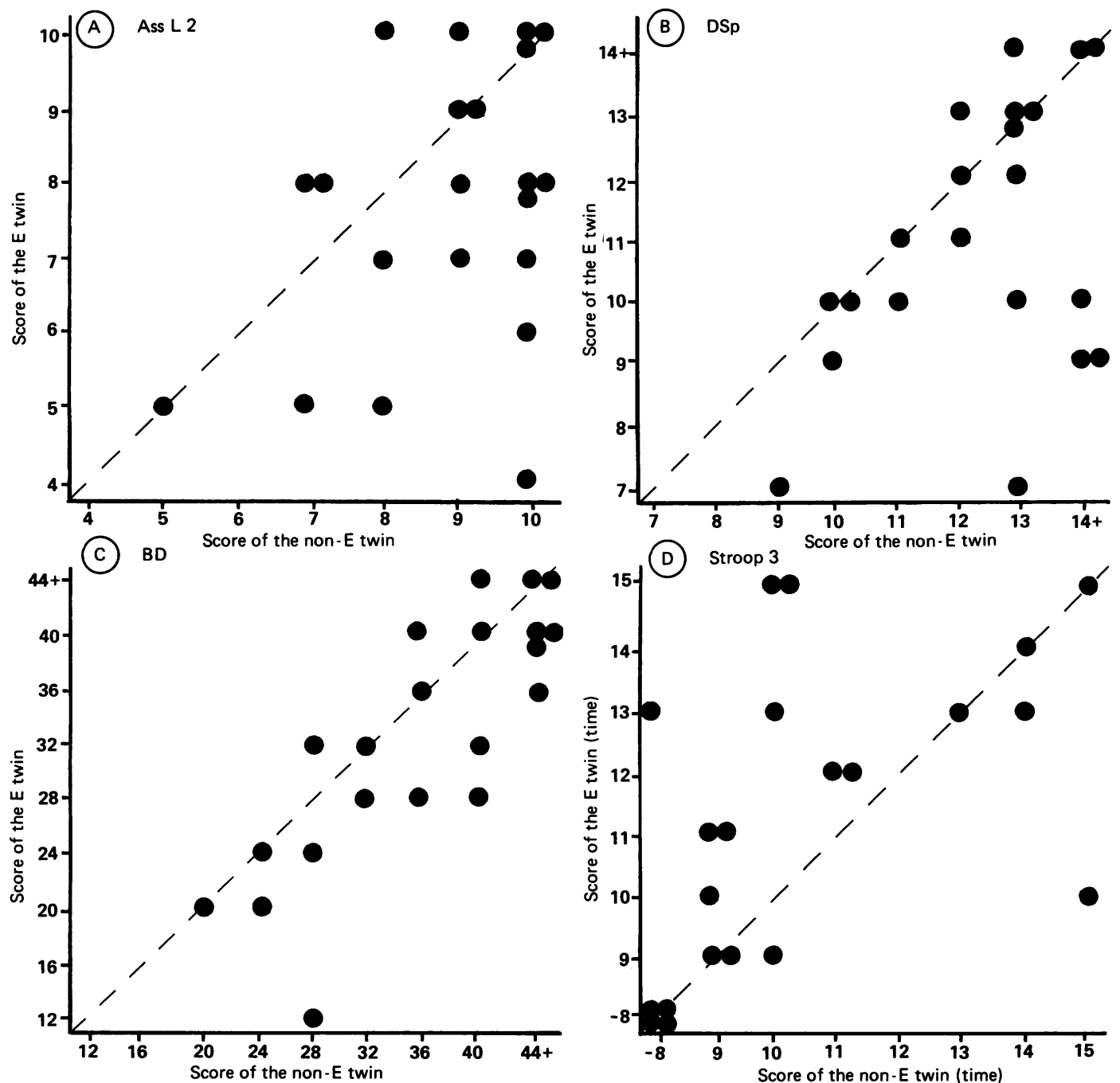

Scores of the exposed twins (E) in four tests, plotted against the scores of their cotwins (non-E). A: AssL2, raw score; $B: D S p$, raw score; $C: B D$, raw score; $D:$ Stroop3, performance time in 10 seconds.

The CID score had, as expected, a near normal distribution within the $S$ pairs. The proportion of pairs with $\operatorname{CDS}$ between +1 and -1 was $71 \%$ compared with $38 \%$ for the $S$ pairs $(p<0.05)$ (table 8). Distributions of the CID score also differed significantly between the subgroups $(p<0.05)$. Seven of the E2 twins had a CID score below -2 compared with none of the E1 twins. The mean CID score was -0.8 for the E1 twins and -2.9 for the E2 twins.

The seven $\mathrm{E}$ twins who had not been exposed to solvents during the past two to 16 years were affected less than those who were still working with solvents.
The mean CID was -1.6 for those not recently working with solvents, and $-\mathbf{2 \cdot} 2$ for those who were; the difference was not statistically significant. Four of the seven differed from their cotwins in AssL, and all but one did worse than the cotwins in one to three test parameters.

Intrapair differences in POMS and MPI scales were too few and unsystematic to warrant calculation of any kind of composite difference scores.

\section{Discussion}

The strength of our study was the use of monozygotic 
Table 6 Mean intrapair differences in the solvent pairs $(S)$ $(n=21)$ and reference pairs $(R)(n=28):$ POMS and $M P I$

\begin{tabular}{|c|c|c|c|c|}
\hline & \multicolumn{2}{|l|}{ Solvent pairs } & \multicolumn{2}{|c|}{ Reference pairs } \\
\hline & Mean (SD) & $t^{\dagger}$ & $\operatorname{Mean}(S D)$ & $t^{\dagger}$ \\
\hline \multicolumn{5}{|c|}{ Profile of mood states } \\
\hline Tension & $0.2(3.3)$ & $0 \cdot 266$ & $0.4(3.0)$ & 0.702 \\
\hline Depression & $-1.0(3.3)$ & $-1 \cdot 313$ & $1 \cdot 1(5 \cdot 0)$ & $1 \cdot 143$ \\
\hline Hostility & $-1.0(5 \cdot 8)$ & -0.833 & $0.0(5 \cdot 6)$ & 0.000 \\
\hline Fatigue & $0.6(3.2)$ & 0.882 & $0.9(2 \cdot 1)$ & $2 \cdot 139^{\star}$ \\
\hline Listlessness & $-0.3(2 \cdot 1)$ & -0.616 & $-0.1(2.6)$ & -0.216 \\
\hline Vigour & $0.4(6.5)$ & $0 \cdot 270$ & $1 \cdot 2(5 \cdot 4)$ & $1 \cdot 163$ \\
\hline Uncertainty & $0 \cdot 7(2 \cdot 8)$ & $1 \cdot 106$ & $0 \cdot 2(4 \cdot 4)$ & 0.259 \\
\hline mindedness & $1 \cdot 2(3 \cdot 0)$ & $1 \cdot 914^{\star}$ & $0.5(2 \cdot 4)$ & $1 \cdot 090$ \\
\hline \multicolumn{5}{|c|}{ Maudsley personality inventory } \\
\hline $\begin{array}{l}\text { Neurotisism } \\
\text { Extroversion }\end{array}$ & $\begin{array}{l}0.1(2 \cdot 2) \\
0.3(2 \cdot 0)\end{array}$ & $\begin{array}{l}0.195 \\
0.662\end{array}$ & $\begin{array}{l}0.4(1.6) \\
0.5(1.8)\end{array}$ & $\begin{array}{l}1 \cdot 285 \\
0 \cdot 662\end{array}$ \\
\hline
\end{tabular}

${ }^{\star} \mathrm{p}<0.05$.

+One sided $t$ test for paired comparisons.

Table 7 Numbers of $E$ twins with better, similar, and worse performance compared with non-E twins in nine test variables (corresponding prevalences of better and worse performances in subgroup $E 2$ in parentheses)

\begin{tabular}{llll}
\hline Variable & $E>$ non- $E$ & Similar & $E<$ non- $E$ \\
\hline AssL2 & $1(1)$ & 11 & $9^{\star}(7)$ \\
DSp & 0 & 17 & $4(2)$ \\
VisR & $2(0)$ & 14 & $5(3)$ \\
BD & 0 & 15 & $6^{\star}(5)$ \\
Stroop2 & $1(0)$ & 15 & $5(4)$ \\
SA2 & 0 & 17 & $4(2)$ \\
FT2 & $3(1)$ & 13 & $5(4)$ \\
Miral & $1(1)$ & 13 & $7 \star(4)$ \\
Mira3 & 0 & 18 & $3(3)$ \\
\hline
\end{tabular}

${ }^{\star} \mathrm{p}<0.05$ (sign test).

Table 8 Distribution of composite difference scores (CDS) in four groups: $S(E 1)=$ exposed subgroup with lower exposure; $S(E 2)=$ subgroup with higher exposure; $S=$ total exposed group; $R=$ reference group

\begin{tabular}{lllll}
\hline$C D 5$ & $\begin{array}{l}S(E 1) \\
(n=11)\end{array}$ & $\begin{array}{l}S(E 2) \\
(n=10)\end{array}$ & $\begin{array}{l}S \\
(n=21)\end{array}$ & $\begin{array}{l}R \\
(n=28)\end{array}$ \\
\hline+4 & & & & 1 \\
+3 & & & 1 & 2 \\
+2 & 1 & & 1 & 5 \\
+1 & 1 & & 7 & 8 \\
0 & & 1 & 5 & 2 \\
-1 & 6 & 2 & 5 & 1 \\
-2 & 3 & 4 & 4 & 2 \\
-3 & & 1 & 1 & \\
-4 & & 2 & 2 & \\
-5 & & 2 &
\end{tabular}

cotwins as controls for the exposed subjects. Previous research has shown that monozygotic twins have relatively similar test performances in the absence of diseases or other factors affecting neurological and behavioural conditions. ${ }^{25} 2627$ The weakness of our material was, on the other hand, the small sample size and exposure that ranged from low to moderate; only five subjects had exposures equalling or exceeding one half of the Finnish Hygiene Standard. Considering the strengths and weaknesses of the study, statistically significant differences between the exposed and non-exposed twins, as well as indications of a dose response relation, can be taken as relatively strong evidence for the behavioural toxicity of organic solvents.

Emphasis was placed on the comparison of test performances between exposed and non-exposed cotwins. Another group of identical twins acted as further reference material for the intrapair differences. Standard deviations of the mean intrapair differences in the single tests did not indicate that the reference pairs were more concordant in their performances than the solvent pairs, except in a few test variables. The intrapair differences were systematic, however, in Group S in two ways; the exposed twins tended to have poorer measures, particularly for the cognitive tasks, and the proportion of twin pairs differing for more than one single test variable was significantly higher in the $S$ pairs than in the $R$ pairs. The one sided $t$ test for paired comparisons gave a statistically significant difference between the exposed and non-exposed cotwins for three of the seven cognitive tests (five of 11 test variables). For the nine psychomotor measures, there was one statistically significant difference in the expected duration and one in the reverse direction. For the reference group, one of twenty test variables showed a statistically significant difference between twins with odd and even numbers (a statistically significant difference caused by change).

Examination of essential intrapair differencesthat is, differences that corresponded to, or exceeded 1SD of the test score-complemented the paired comparisons with $t$ tests. The exposed twins were significantly more often worse in one psychomotor and in two cognitive tests. Three more cognitive and two psychomotor tests showed the same trend but without reaching statistical significance. Distribution of a composite difference score for the $S$ pairs differed markedly from the normal distribution found for the $\mathbf{R}$ pairs. Moreover, an exposure response relation was indicated by comparison of the distribution of composite difference scores for exposure subgroups with a high and low index for the total exposure.

An alternative explanation for the results may be that slight intrapair differences in initial ability have led the less capable twins to less favourable jobs, and that the exposure to solvents is a consequence of lower performance rather than the opposite. Our data, however, do not fit this hypothesis. The occupational state of the $E$ and non-E twins was essentially the same. A similar ability in the test for verbal comprehension (similarities) also suggests no initial differences in intelligence. 
Three of the exposed twins of the less exposed subgroup had less formal education than their cotwins, and had a lower score in one or two tests. The effect of education, or factors related to discordant education, cannot be ruled out in these cases. If the difference was related to exposure, the solvent induced difference between exposed and nonexposed twins could be somewhat less than indicated by our results, but the difference between the two exposure subgroups would be more pronounced.

The time between the last exposure to solvents and the test examination was at least $\mathbf{4 0}$ hours. Thus the effect seems to be related to long term rather than acute exposure. Moreover, the effect found among those who had not been exposed during the past years was only slightly diluted when compared with those still working in situations of exposure.

Our results suggest that exposure to organic solvents affects verbal learning and memory and the cognitive functions required by a visuoconstructive task, and also increases the probability of other types of dysfunctions. The three most sensitive tests in our study-AssL, DSp, and BD-were also the best discriminators in a previous study on differences between car painters exposed to solvents and their referents. ${ }^{5}$ In a study on differences between the clinical solvent syndrome and three other neurological syndromes, DSp and BD were the best discriminating tests. ${ }^{13}$ Possible confounding could not be totally ruled out in the two studies. Nevertheless, these three solvent studies, each using a similar set of tests but different subjects, seem to confirm each others' findings. A lowered score in visual intelligence or in verbal memory tests, or both, has also been reported in other studies on the effects of mixtures of organic solvents. ${ }^{628} 29$

Effects on visual memory reported in some earlier studies ${ }^{418}$ could not be confirmed in our study. The same applies to the psychomotor functions. The exposed twins were more often worse than their cotwins with regard to the control of hand movements (SA2 and Mira), but only one of the Mira variables showed a statistically significant difference. Moreover, the exposed people tended to be faster in some psychomotor speed tests. Some previous studies on solvent mixtures ${ }^{728}$ have shown retardation of psychomotor speed, but other studies dealing with low exposures have given negative results. ${ }^{918}$ We were not able to replicate earlier results concerning mood and personality changes either. ${ }^{578}$ This negative result may be due to low exposure and to low sensitivity of the methods.

The neuropsychological dysfunctions related to exposure ranged from subtle to moderate. Even in the presence of a clear intrapair difference, most of the exposed persons still performed within the normal range, though at a lower level than their cotwins. They would have been considered as unaffected if assessed as single individual cases without the possibility of comparing the test scores with their initial level, which in this study was assumed to be close to that exhibited by the cotwins. For some others, the only indicator for a possible adverse effect would have been a low score in the associative learning test. Our results draw attention to the difficulty of detecting subtle or even moderate dysfunctions, particularly in subjects whose initial capabilities are high and who, after considerable change, may still obtain average or low average scores in a test examination. The biological significance of these changes and their practical significance in every day situations are difficult to assess, particularly at the individual level. When evaluated at group level, our results indicate a slight effect on the nervous system at low to moderate exposure and thus confirm earlier studies on exposure to mixtures of organic solvents. ${ }^{45781828}$

The authors thank Kaarina Rantala (MSc) who evaluated the degree of exposure during the subjects' entire history of exposure. Her excellent acquaintance with solvents in the work environment was of great value for our study.

Requests for reprints to: $\mathrm{PhL}$ Helena Hänninen, Institute of Occupational Health, Topeliuksenkatu 41 a A, 00250 Helsinki, Finland.

1 Cherry N, Hutchins H, Pace T, Waldron A. Neurobehavioural effects of repeated occupational exposure to toluene and paint solvents. Br J Ind Med 1985;42:291-300.

2 Maizlish NA, Langof GB, Whitehead LW, et al. Behavioural evaluation of workers exposed to mixtures of organic solvents. Br J Ind Med 1985;42:570-90.

3 Triebig G, Claus D, Csuzda I, et al. Cross-sectional epidemiological study on neurotoxicity of solvent paints and lacquers. Int Arch Occup Environ Health 1988;60:233-41.

4 Hane M, Axelson O, Blome J, Hogstedt C, et al. Psychological function changes among house painters. Scand J Work Environ Health 1977;3:91-9.

5 Hänninen H, Eskelinen L, Husman K, Nurminen N. Behavioral effects of long-term exposure to a mixture of organic solvents. Scand $J$ Work Environ Health 1976;2:240-55.

6 Valciukas JA, Lilis R, Singer R, Glickman L, et al. Neurobehavioral changes among shipyard painters exposed to solvents. Int Arch Occup Health 1985;40:47-52.

7 Elofson SA, Gamberale F, Hindmarsch T, Iregren A, et al. Exposure to organic solvents: a cross-sectional epidemiologic investigation on occupationally exposed car and industrial spray painters with special reference to the nervous system. Scand J Work Environ Health 1976;2:240-55.

8 Baker EL, Letz RE, Eisen EA, Pothier LJ, et al. Neurobehavioral effects of solvents in construction painters. J Occup Med 1988;30:116-23.

9 Orbaek P, Risberg J, Rosen I, Haeger-Aronsen B, et al. Effects of long-term exposure to solvents in paint industry. Scand $J$ Work Environ Health 1985;suppl 2:1-28.

10 Kaprio J, Koskenvuo M, Artimo M, Rantasalo I. Baseline characteristics of the Finnish Twin Registry: section I: materials, methods, representativeness and results for variables special to twin studies. Helsinki: Kansanterveystieteen julkaisuja M47, 1979.

11 ACGIH. Threshold limit values for chemical substances in the work environment adopted by ACGIH with intended changes for 1985-86. American conference of governmental industrial hygienists, Cincinnati 1985. (ISBN 0-936712-61-9.)

12 Juntunen J, Matikainen E, Antti-Poika M, et al. A co-twin 
control study of nervous system structure and function in occupational solvent exposure. In: XXIIth International congress on occupational health, Sydney, Australia, 1987:172. (Abstract.)

13 Eskelinen L, Luisto M, Tenkanen L, Mattei, O. Neuropsychological methods in the differentiation between organic solvent intoxication from certain neurological conditions. $J$ Clin Exp Neuropsychol 1986;8:239-56.

14 Hänninen $\mathrm{H}$. Psychological picture of manifest and latent carbon disulphide poisoning. $\mathrm{Br} J$ Ind Med 1971;28:374-81.

15 Hänninen H, Antti-Poika M, Savolainen P. Psychological performance, toluene exposure and alcohol consumption in rotogravure printers. Int Arch Occup Environ Health 1978;59:475-83.

16 Lindström K. Changes in psychological performances of solvent-poisoned and solvent-exposed workers. Am J Ind Med 1980;1:69-84.

17 Lindström $\mathrm{K}$, Härkönen $\mathrm{H}$, Hernberg $\mathrm{S}$. Disturbances in psychological functions of workers occupationally exposed to styrene. Scand JWork Environ Health 1976;3:129-39.

18 Lindström K, Wickström G. Psychological function changes among maintenance house painters exposed to low levels of organic solvent mixtures. Acta Psychiatr Scand 1983;67(suppl 303):81-91.

19 Hänninen H, Rantala K, Tuominen E. Neuropsychological and subjective dysfunctions as markers of an early neurotoxic effect: a combined screening system for occupational health services. J Occup Med (submitted).

20 Wechsler D. WAIS manual. Wechsler adult intelligence scale.
New York: The Psychological Corporation, 1955.

21 Wechsler D. WAIS-R manual. Wechsler adult intelligence scale, Revised ed. New York: The Psychological Corporation, 1981.

22 Wechsler D. A standardized memory scale for clinical use $J$ Psychol 1945;19:87-95.

23 Valciukas JA, Singer RM. The embedded figures test in epidemiological studies of environmental neurotoxic agents. Environmental Sciences Laboratory, Mount Sinai School of Medicine, New York 1979.

24 Hänninen H, Lindström K. Neurobehavioral test battery of the Institute of Occupational Health. Helsinki: Institute of Occupational Health Reviews 1989;15:5-6.

25 Marsh RW. The significance for intelligence of differences in birth-weight and health within monozygotic twin pairs. $\mathrm{Br}$ Psychol 1980;71:63-7.

26 Partanen J, Bruun K, Markkanen T. Inheritance of drinking behavior. Helsinki: The Finnish Foundation for Alcohol Studies, 1966

27 Tumbs K, Sundet JM, Magnus P. Hereditary analysis of the WAIS subtests: A study of twins. Intelligence 1984;8:283-93.

28 Fidler A, Baker EL, Letz RE. Neurobehavioural effects of occupational exposure to organic solvents among construction painters. Br J Ind Med 1978;44:292-308.

29 Orbaek $\mathrm{P}$, Lindgren $M$. Prospective clinical and psychological investigation of patients with chronic toxic encephalopathy induced by solvents. Scand J Work Environ Health 1988; $14: 37-44$.

Accepted 6 July 1990

\section{Correspondence and editorials}

The British Journal of Industrial Medicine welcomes correspondence relating to any of the material appearing in the journal. Results from preliminary or small scale studies may also be published in the correspondence column if this seems appropriate. Letters should be not more than 500 words in length and contain a minimum of references. Tables and figures should be kept to an absolute minimum. Letters are accepted on the understanding that they may be subject to editorial revision and shortening.

The journal now also publishes editorials which are normally specially commissioned. The Editor welcomes suggestions regarding suitable topics; those wishing to submit an editorial, however, should do so only after discussion with the Editor. 